\title{
Role of Articular Disc in Condylar Regeneration of the Mandible
}

\author{
Hidetaka HAYASHI, Tadashi FUJITA, Maya SHIRAKURA, Yuji TSUKA, Eri FUJII, Akiko TERAO, \\ and Kotaro TANIMOTO \\ Department of Orthodontics and Craniofacial Developmental Biology, Hiroshima University Graduate School \\ of Biomedical Science, 1-2-3 Kasumi, Minami-ku, Hiroshima 734-8553, Japan
}

\begin{abstract}
The articular disc in the temporomandibular joint plays an important role in mandibular growth. Functional appliances induce regeneration of the condyle even after condylectomy. The aim of this study was to examine the role of the articular disc in regeneration of the condyle after unilateral condylectomy with use of a functional appliance in growing rats. Fifty growing rats were subjected to unilateral condylectomy and then half of them underwent discectomy. The functional appliance was applied to half of the rats in each group to induce regeneration of the condyle. Four and eight weeks later, morphometric and histologic analyses of the mandible were performed. Regeneration of the condyle was demonstrated in the two condylectomy groups. In the condylectomy+appliance group, the shape and cartilage of the condyle were equivalent to a normal condyle. However, regeneration of the condyle was not observed in the two discectomy groups even with the use of the functional appliance. The articular disc appears to be crucial in the regeneration of a damaged condyle, suggesting that defects or damage to the articular disc may influence mandibular growth and regeneration or repair of the condyle.
\end{abstract}

Key words: articular disc

\section{Introduction}

The condyle is considered the main growth site of mandible. The temporomandibular joint (TMJ) helps eliminate friction between the condyle and the glenoid fossa. The absence of the TMJ due to discectomy induces histological changes in the condylar cartilage [11]. Several clinical studies on facial asymmetry and mandibular retrognathia in children and adolescents have reported an association of these conditions with coexisting irreducible displacement of the TMJ disc $[7,15,17,19,20,22]$. In animal experiments, TMJ disc displacement was shown to induce histological changes in the condylar cartilage and exert a substantial influence on mandibular growth [1]. The articular disc regulates the condylar biomechanical environment in the TMJ and affects mandibular growth.

Condylar regeneration has been discussed in some clinical reports $[9,23]$ and some studies have reported condylar regeneration in the mandible after experimental condylectomy of animals during their growing period $[13,14,16]$. In recent years, Fujita et al. [6] confirmed mesenchymal cell aggregation in the resected area in the early condylectomized stage when an appliance was used, suggesting the existence of an environment adequate for cartilage regeneration. Although studies confirm regeneration of the condyle within the appropriate biomechanical environment, the role of the articular disc during condylar regeneration is unclear. This study examines the role of the articular disc in condylar regeneration after condylectomy with the use of functional appliances in rats.

(Received 17 February 2014 / Accepted 17 April 2014 / Published online in J-STAGE 15 July 2014)

Address corresponding: H. Hayashi, Department of Orthodontics and Craniofacial Developmental Biology, Applied Life Sciences, Hiroshima

University Institute of Biomedical \& Health Sciences; 1-2-3 Kasumi, Minami-ku, Hiroshima 734-8553, Japan

(C2014 Japanese Association for Laboratory Animal Science 


\section{Materials and Methods}

This study was based on the methods described by Fujita et al. (2013) [6], who collected samples and data from a sham-operated control group and condylectomy experimental groups with and without functional appliance.

Fifty male Wistar rats were randomly divided into five groups: control, condylectomy (Cd), condylectomy +discectomy $(\mathrm{Cd}+\mathrm{Dc})$, condylectomy +appliance $(\mathrm{Cd}+\mathrm{Appl})$, and condylectomy+discectomy+appliance group $(\mathrm{Cd}+\mathrm{Dc}+\mathrm{Appl})$. At age 4 weeks, unilateral condylectomy was performed in the $\mathrm{Cd}$ and $\mathrm{Cd}+\mathrm{Appl}$ groups and unilateral condylectomy and discectomy were performed in the $\mathrm{Cd}+\mathrm{Dc}$ and $\mathrm{Cd}+\mathrm{Dc}+\mathrm{Appl}$ groups. The functional appliance was immediately applied to the $\mathrm{Cd}+\mathrm{Appl}$ and $\mathrm{Cd}+\mathrm{Dc}+\mathrm{Appl}$ groups after surgery.

All rats were fed a soft diet (CE-2; Clea, Tokyo, Japan) with water ad libitum. Body weight was measured every 2-3 days during the experiment and was used as an indicator of general growth. Rats were sacrificed by perfusion fixation under general anesthesia with pentobarbital (Somnopentyl; Kyoritsu, Tokyo, Japan) 4 and 8 weeks after surgery.

All experiments were approved by the Animal Experimentation Committee at Hiroshima University and complied with the ARRIVE guidelines for animal research [8] as well as the Hiroshima University Rules for Animal Experiments.

TMJ disc excision was performed under general anesthesia with pentobarbital (Somnopentyl; Kyoritsu). A horizontal incision was made 5-7 mm below the left zygomatic arch, exposing the superficial masseter muscle fibers. The fibers were then separated by blunt and sharp dissection until the mandibular ramus and condyle were exposed.

The joint disc was fully exposed and carefully resected with scissors and a knife without any injury to the articular surface. The condylar neck was cut with scissors, and the condyle was removed so as not to leave any condylar cartilage.

Close inspection ensured that a clean and complete discectomy had been performed. Muscle fibers were returned to the original position and the incision was closed with sutures. These procedures were performed under sterile conditions. Control rats underwent a sham procedure in the condylar area on the left side.

Rats were anesthetized with pentobarbital to undergo a CT scan (Somnopentyl; Kyoritsu). We used a micro-CT (R_mCT ${ }^{\circledR}$; Rigaku Co., Tokyo, Japan) at a magnification of 6.7 fold (voxel size: $50 \mu \mathrm{m}^{3}$ ), tube voltage of $90 \mathrm{kv}$, and tube current of $50 \mu \mathrm{A}$. The i-view- ${ }^{\circledR}$ (J. Morita Mfg. Corp., Kyoto, Japan) image reconstruction software was used. The field of view was $24 \times 24 \times 24 \mathrm{~mm}$ (pixel number: $480 \times 480 \times 480$ ), and scanning time was $17 \mathrm{~s}$. A micro-CT scan of the condyle was done 1, 2, 4, 6 , and 8 weeks after surgery.

At 4 and 8 weeks after surgery, both TMJs were dissected out and placed in formalin, according to the method of Fujita et al. [6]. Specimens were decalcified in ethylenediaminetetraacetic acid (EDTA). Sagittal sections $(7 \mu \mathrm{m})$ were stained with hematoxylin and eosin (H-E) for histological observation using a digital camera (Biozero; Keyence, Osaka, Japan) and analysis software (BZ-II Analyzer, Keyence).

Lateral cephalograms were obtained for all rats at 4 and 8 weeks after surgery, according to the method of Fujita et al. [6]. The head of each animal was fixed and halved on the median sagittal plane. We placed the halved left side of the head on dental occlusal film (DF50; Eastman Kodak, Rochester, NY), and cephalograms were obtained under electronic controls of $6 \mathrm{~mA}$ and $30-35 \mathrm{Kvp}$ with an exposure time of $3.0 \mathrm{~s}$.

On lateral cephalograms, landmarks and measurement items were established according to the method of $\mathrm{Fu}$ jita et al. [4] (Fig. 1). We measured the point on the most inferior contour of the lower border of the mandible, adjacent to the incisors (Me), as well as the most posterior point of the angular process of the mandible (MeGo), the most posterosuperior point of the condylar process $(\mathrm{Me}-\mathrm{Cd})$, and the most posterior point of the coronoid process of the mandible (Me-Co).

Morphometric analysis of the mandible was performed three times for each measurement item. Means of traced lateral cephalograms in each group were superimposed on the Me-Gn line; Gn point was on the most inferior contour of angular process of mandible, at Me to compare morphologic differences between groups.

We used the unpaired $t$ test to examine differences in measured values among groups, after the presence of a normal distribution and equality of variance (F-test) were checked for all variables. All statistical analyses were performed with Excel Statistical 2013 (Microsoft, Redmond, WA, USA). Differences were considered significant at $P<0.05$.

Ten randomly drawn lateral cephalograms from the 


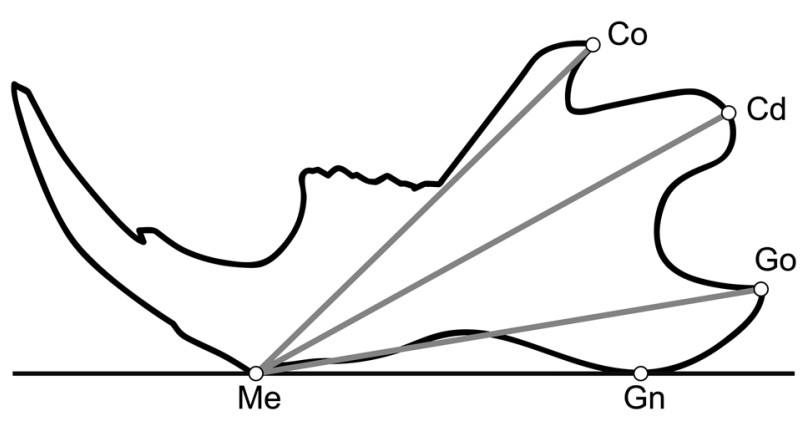

Fig. 1. Landmarks used for cephalometric analyses. Me-Go, Me$\mathrm{Cd}$, and $\mathrm{Me}-\mathrm{Co}$ were measured.

$\mathrm{Me}$, Point on the most inferior contour of the lower border of the mandible, adjacent to the incisors; Go, Most posterior point of the angular process of the mandible; $\mathrm{Cd}$, Most posterosuperior point of the condylar process; Co, Most posterior point of the coronoid process of the mandible; Gn, Point on the most inferior contour of the angular process of the mandible.

250 films were quantified on two separate occasions about 2 months apart to calculate the method error (ME). ME in measuring the areas of the staining was calculated by the formula: $\sqrt{\sum d^{2} / 2 \mathrm{n}}$ is the difference between the two registrations, and $n$ is the number of double registrations. Hypothesis testing indicated no significant difference among the registrations for mandibular measurement items.

\section{Results}

Body weight increased from 109 to $388 \mathrm{~g}, 104$ to $370 \mathrm{~g}, 107$ to $423 \mathrm{~g}$, and 115 to $418 \mathrm{~g}$ in the Cd group, the $\mathrm{Cd}+\mathrm{Appl}$ group, the $\mathrm{Cd}+\mathrm{Dc}$ group, and the $\mathrm{Cd}+\mathrm{Dc}+\mathrm{Appl}$ group, respectively. In the control group, body weight increased from 103 to $393 \mathrm{~g}$. Although there was a significant difference in body weight between groups at 21 and 24 days after surgery, no significant differences were observed at the remaining time points (see appendix: refer to J-STAGE: https://www.jstage.jst. go.jp/browse/expanim).

Condyles of the experimental group exhibited morphologic changes on micro-CT imaging at 1, 2, 4, 6, and 8 weeks. In the $\mathrm{Cd}, \mathrm{Cd}+\mathrm{Appl}, \mathrm{Cd}+\mathrm{Dc}$ and $\mathrm{Cd}+\mathrm{Dc}+\mathrm{Appl}$ groups, condyle with an irregular shape was initiated at 1 and 2 weeks. In the Cd group, the condyle which was shorter and more irregular than in the control group was observed at 4, 6 and 8 weeks. In the $\mathrm{Cd}+\mathrm{Appl}$ group, condylar form was observed at the end of the experiment. In particular, compared with the $\mathrm{Cd}$ group, the condyle
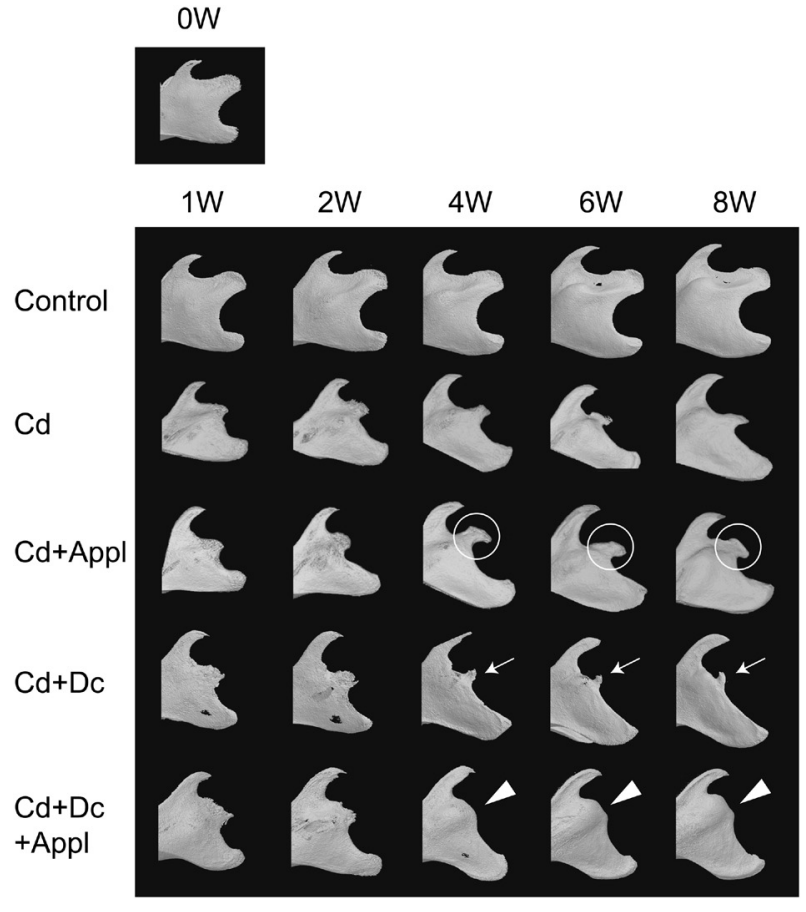

Fig. 2. Micro-CT image of the control and experimental groups at $0,1,2,4,6$ and 8 weeks.

In the Cd group, the condyle which was shorter and more irregular than in the control group, was observed at 4, 6 and 8 weeks. In the $\mathrm{Cd}+\mathrm{Appl}$ group, the condyle which was longer with a more prominent constricted shape of the neck than in the Cd group, was confirmed after 8 weeks by circles. In the $\mathrm{Cd}+\mathrm{Dc}$ group, only a short process with linear base was seen at 4,6 , or 8 weeks by arrows. In $\mathrm{Cd}+\mathrm{Dc}+$ Appl group, a tubercle with wide base at the position of condylar process was observed at 4,6 , or 8 weeks by arrow heads.

was recognized to have condylar neck at 4,6 , and 8 weeks. In the $\mathrm{Cd}+\mathrm{Dc}$ and $\mathrm{Cd}+\mathrm{Dc}+\mathrm{Appl}$ groups, condylar continuously lengthen with time was not observed at 4,6 , or 8 weeks. It was seen only a short process with linear base in the $\mathrm{Cd}+\mathrm{Dc}$ group at 4,6 , or 8 weeks and a tubercle with wide base at the position of condylar process in $\mathrm{Cd}+\mathrm{Dc}+\mathrm{Appl}$ group at 4,6 , or 8 weeks (Fig. 2).

Figure 3 shows H-E stained sagittal TMJ sections in each group. In the control animals, the condyles exhibited a round shape and a smooth articular surface with no pathologic signs. Cartilage layers were clearly distinguished, and cells were regularly arranged. In the $\mathrm{Cd}$ and $\mathrm{Cd}+\mathrm{Appl}$ groups, condylar cartilage was observed at 4 and 8 weeks. In particular, the regenerated condyle in the $\mathrm{Cd}+\mathrm{Appl}$ group was similar to that in the control group, with a rounded form and cartilage layers covering 


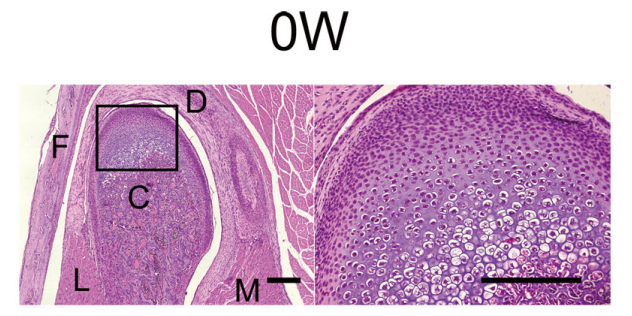
D: articular disc
C: condylar head
$\mathrm{F}:$ glenoid fossa
$\mathrm{L}$ : lateral pterygoid muscle
M: Masseter muscle

Immediately after condylectomy (left), condylectomy and discectomy (right)
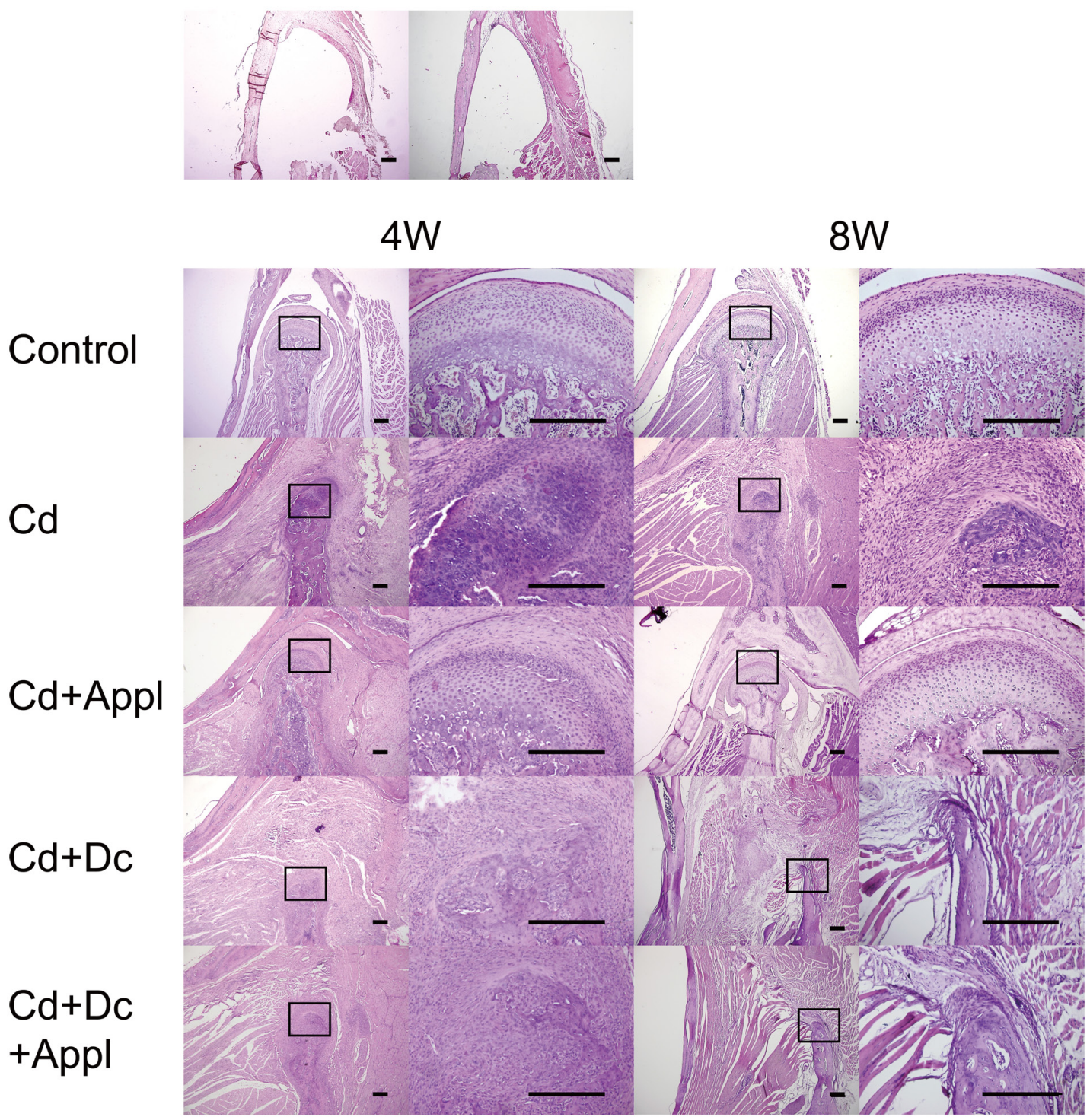

Fig. 3. H-E stained sections of rat condyle at 0 (control, immediately after condylectomy and immediately after condylectomy with discectomy), 4 , and 8 weeks.

The area contained within each square is enlarged in the images on the right side (Bar=300 $\mu \mathrm{m})$.

the surface of the condyle (Fig. 3).

On the other hand, the condyle in the $\mathrm{Cd}+\mathrm{Dc}$ and $\mathrm{Cd}+\mathrm{Dc}+$ Appl groups became thinner than in the control group and showed similar morphologic formations to each other. At 4 weeks, the condyle in the $\mathrm{Cd}+\mathrm{Dc}$ and $\mathrm{Cd}+\mathrm{Dc}+$ Appl groups showed little cartilage around the 

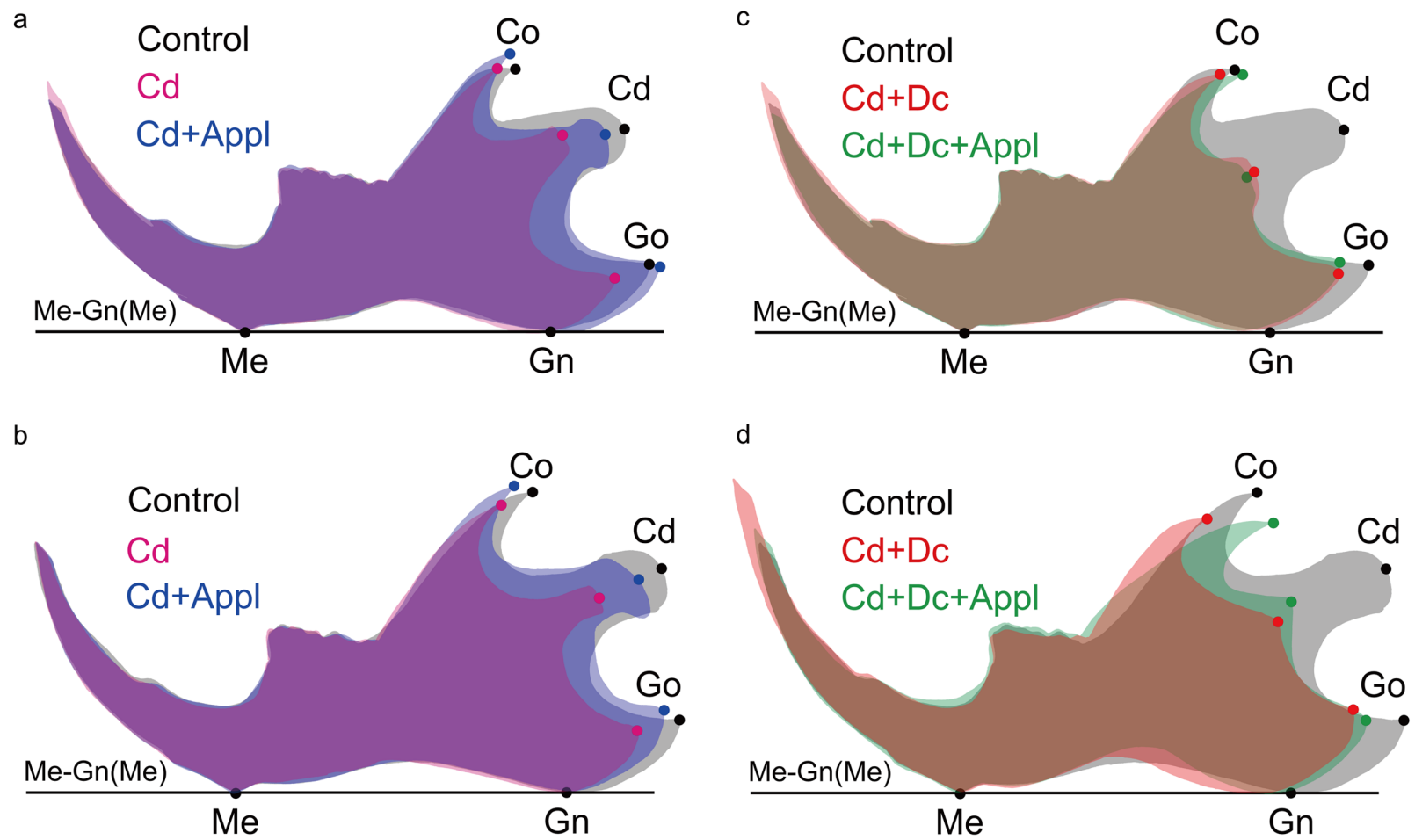

e
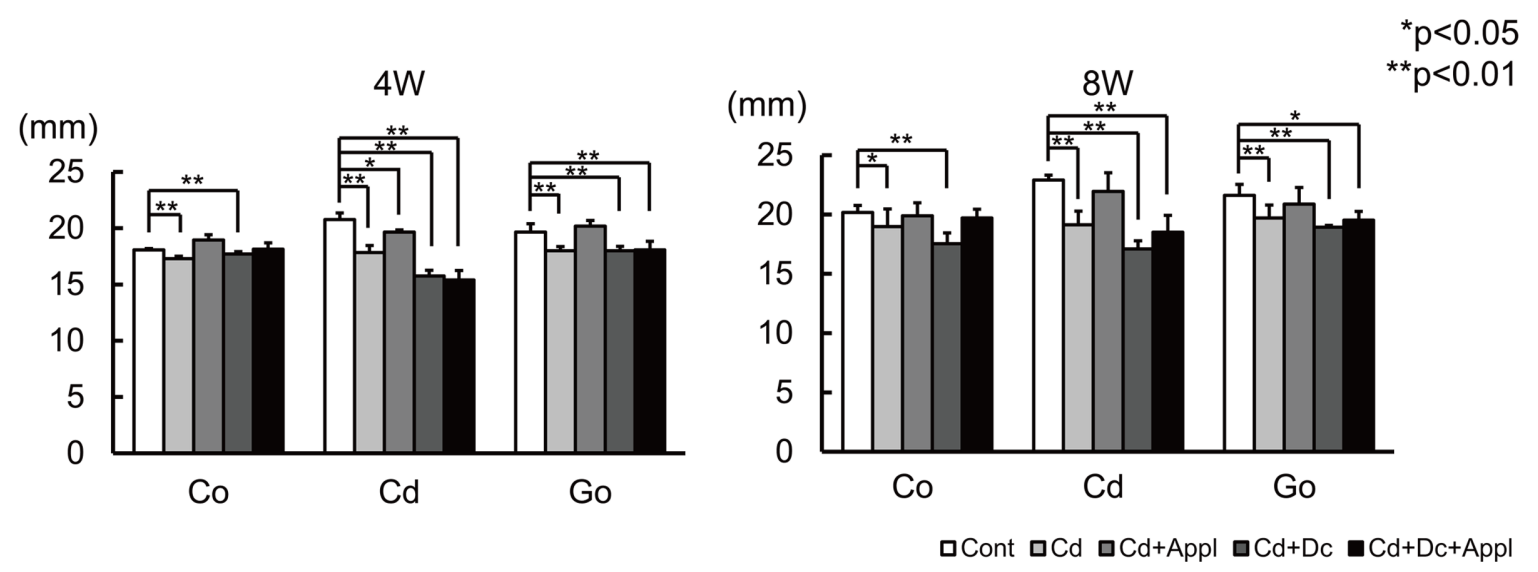

Fig. 4. Superimposition of mean tracings on the Me-Gn line at Me.

(a) Comparison of mandibular measurements in the control, $\mathrm{Cd}$, and $\mathrm{Cd}+\mathrm{Appl}$ groups at 4 weeks and (b) 8 weeks. (c) Comparison of mandibular measurements in the control, $C d+D c$, and $C d+D c+A p p l$ groups at 4 weeks and (d) 8 weeks. (e) Size of the mandible in each group at 4 and 8 weeks.

condyle and no cartilage layers. At 8 weeks, regeneration of cartilage was not seen in the condyle surface, which was covered by fibrous tissue instead of cartilage (Fig. 3).

On the superimposed lateral cephalogram tracings at week 4 , Me-Co, Me-Cd, and Me-Go were significantly lower in the $\mathrm{Cd}$ group than in the control group. In the $\mathrm{Cd}+$ Appl group, Me-Cd was significantly lower than in the control group (Figs. 4a and e). On the other hand, no significant differences in the size of the mandible were observed between the $\mathrm{Cd}+\mathrm{Appl}$ group and control group at 8 weeks despite significant differences in the Me-Co, $\mathrm{Me}-\mathrm{Cd}$, and $\mathrm{Me}-\mathrm{Go}$ between the $\mathrm{Cd}$ and control groups (Figs. $4 \mathrm{~b}$ and e).

At 4 weeks, Me-Co, Me-Cd, and Me-Go were significantly lower in the $\mathrm{Cd}+\mathrm{Dc}$ group than in the control group. In the $\mathrm{Cd}+\mathrm{Dc}+\mathrm{Appl}$ group, $\mathrm{Me}-\mathrm{Cd}$ and $\mathrm{Me}-\mathrm{Go}$ were significantly lower than in the control group (Figs. $4 \mathrm{c}$ and e). In the $\mathrm{Cd}+\mathrm{Dc}$ group, $\mathrm{Me}-\mathrm{Co}, \mathrm{Me}-\mathrm{Cd}$, 
and Me-Go were significantly lower than in the control group and Me-Cd and Me-Go were significantly lower in the $\mathrm{Cd}+\mathrm{Dc}+\mathrm{Appl}$ group than in the control group at 8 weeks (Figs. 4d and e).

\section{Discussion}

In this study, we aimed to shed light on the role of the articular disc in condylar regeneration after condylectomy. We used 4-week-old male rats because their growth rate is fast [18].The 8-week observation period was based on a study by Fujta et al. [6] and histological analysis was conducted at 4 and 8 weeks to decisively evaluate decisive regeneration. A certain degree of weight loss was observed in all rats that underwent surgery and then all the animals exhibited normal growth without any significant differences among groups, indicating that the experimental procedures did not have a substantial influence on general growth. In previous study, it is observed that functional appliance altered mandibular position and extend condylar cartilage layer in histology [6]. In this study, the same appliance was used and similar phenomenon was also observed in experimental opposite side.

Condylar regeneration appeared in the $\mathrm{Cd}$ and $\mathrm{Cd}+$ Appl groups regardless of functional appliance installed, although there was a difference in the extent of condylar regeneration between these two groups. On the other hand, no regeneration was observed in the $\mathrm{Cd}+\mathrm{Dc}$ and $\mathrm{Cd}+\mathrm{Dc}+\mathrm{Appl}$ groups. Wong et al. [21] reported growth of fibrous and cortical bone tissues without hyaline cartilage on the condylar surface in rabbits after condylectomy and discectomy. They also reported that autologous pericranial graft resurfacing was performed after condylectomy and discectomy, and showed regenerated condyle with hyaline cartilage; they concluded that pericranial grafts controlled oxygen tension in the TMJ. Relatively low oxygen tension favors differentiation into cartilage cells, which occurs on the articular surface [10]. Fujita et al. [6] reported that mesenchymal cell aggregation in the resection area was confirmed in the early stage of condylar regeneration. The articular disc may control oxygen tension on the condylar surface after condylectomy and affect mesenchymal cell differentiation to condylar cartilage. The TMJ disc may play a key role in condylar regeneration after condylectomy. Miyamoto et al. [12] reported that the condyle was regenerated in the medial side better than in the lateral side in an experimental condylecomized lamb model. They concluded that because it is easier to injure the disc by performing the condylectomy on the lateral side than the medial side, regeneration on the lateral side was less likely.

The mandibular condyle is an important growth site for the mandible and has an essential ability to control cartilaginous growth of the mandible and internal structures. Fujita et al. [5] showed that the regenerated condyle had normal growth ability with endochondral ossification after condylectomy in growing rats with mandibular advancement appliances. In this study, the $\mathrm{Cd}+\mathrm{Dc}$ and $\mathrm{Cd}+\mathrm{Dc}+\mathrm{Appl}$ groups did not show a regenerated condyle and showed significantly less mandibular growth compared with controls. These results indicate that condylar cartilage loss leads to less mandibular growth in a rapid growing period, and that cartilage has a primary role in mandibular growth. Use of a mandibular advancement appliance mainly affects regenerated condylar cartilage after condylectomy due to mandibular growth. In the $\mathrm{Cd}+\mathrm{Dc}$ group, $\mathrm{Me}-\mathrm{Co}, \mathrm{Me}-\mathrm{Cd}$, and $\mathrm{Me}-\mathrm{Go}$ measurements were significantly lower than in the control group, whereas in the $\mathrm{Cd}+\mathrm{DC}+\mathrm{Appl}$ group, $\mathrm{Me}-\mathrm{Co}$ was similar to controls. The coronoid process attaches to the temporalis of the masticatory muscles. Mandible growth consists of two patterns: endochondral ossification and membranous ossification. From the insertion to the aponeurosis or periosteum, muscles exert force on bones; as a result, bone remodels to attain the shape that can best withstand the mechanical loads applied as membranous ossification $[2,3]$. In orthodontic functional appliance therapy, the functional appliance influences masticatory muscle activity involved in temporalis [20] to adjust the mandibular form. A part of the mandibular remodeling occurs with the functional appliance and may represent membranous ossification caused by activated masticatory muscle. The results of the present study show the use of the appliance partly affects bone remodeling by the attached activated muscle without affecting condylar cartilage. In addition, $\mathrm{Cd}+\mathrm{Dc}+\mathrm{Appl}$ group showed a tubercle with wide base at the position of condylar process comparing to a short process with linear base in $\mathrm{Cd}+\mathrm{Dc}$ group at 8 weeks on CT images. These observation indicated that the functional appliance could accelerate bone modeling, although it could not induce cartilage formation.

In conclusion, regeneration of the condyle was not observed regardless of the presence or absence of a func- 
tional appliance for mandibular advancement after condylectomy and discectomy. Enhanced mandibular growth was rarely affected by the functional appliance for mandibular advancement in growing rats that underwent condylectomy and discectomy. The articular disc is important for condylar regeneration after condylectomy in rats.

\section{References}

1. Bryndahl, F., Warfvinge, G., Eriksson, L., and Isberg, A. 2011. Cartilage changes link retrognathic mandibular growth to TMJ disc displacement in a rabbit model. Int. J. Oral Maxillofac. Surg. 40: 621-627. [Medline] [CrossRef]

2. Dörfl, J. 1980. Migration of tendinous insertions. I. Cause and mechanism. J. Anat. 131: 179-195. [Medline]

3. Dörfl, J. 1980. Migration of tendinous insertions. II. Experimental modifications. J. Anat. 131: 229-237. [Medline]

4. Fujita, T., Ohtani, J., Shigekawa, M., Kawata, T., Kaku, M., Kohno, S., Tsutsui, K., Tenjo, K., Motokawa, M., Tohma, Y., and Tanne, K. 2004. Effects of sex hormone disturbances on craniofacial growth in newborn mice. J. Dent. Res. 83: 250-254. [Medline] [CrossRef]

5. Fujita, T., Nakano, M., Ohtani, J., Kawata, T., Kaku, M., Motokawa, M., Tsuka, N., Hayashi, H., and Tanne, K. 2010. Expression of Sox 9 and type II and X collagens in regenerated condyle. Eur. J. Orthod. 32: 677-680. [Medline] [CrossRef]

6. Fujita, T., Hayashi, H., Shirakura, M., Tsuka, Y., Fujii, E., Kawata, T., Kaku, M., Ohtani, J., Motokawa, M., and Tanne, K. 2013. Regeneration of condyle with a functional appliance. J. Dent. Res. 92: 322-328. [Medline] [CrossRef]

7. Gidarakou, I.K., Tallents, R.H., Kyrkanides, S., Stein, S., and Moss, M.E. 2004. Comparison of skeletal and dental morphology in asymptomatic volunteers and symptomatic patients with bilateral disk displacement without reduction. Angle Orthod. 74: 684-690. [Medline]

8. Kilkenny, C., Browne, W.J., Cuthill, I.C., Emerson, M., and Altman, D.G. 2012. Improving bioscience research reporting: the ARRIVE guidelines for reporting animal research. Osteoarthritis Cartilage 20: 256-260. [Medline] [CrossRef]

9. Kobayashi, T., Takagi, R., Ono, K., Iida, A., Usui, Y., and Ajima, H. 2004. Two children with complete condylar process fractures caused by falling from the front child seats of bicycles. Jpn. J. Oral Maxillofac. Surg. 50: 231-234. [CrossRef]

10. Merceron, C., Vinatier, C., Portron, S., Masson, M., Amiaud, J., Guigand, L., Chérel, Y., Weiss, P., and Guicheux, J. 2010. Differential effects of hypoxia on osteochondrogenic potential of human adipose-derived stem cells. Am. J. Physiol. Cell Physiol. 298: C355-C364. [Medline] [CrossRef]

11. Miyaki, K., Murakami, K., Segami, N., and Iizuka, T. 1994.
Histological and immunohistochemical studies on the articular cartilage after experimental discectomy of the temporomandibular joint in rabbits. J. Oral Rehabil. 21: 299-310. [Medline] [CrossRef]

12. Miyamoto, H., Matsuura, H., Jones, R.H., Kurita, K., and Goss, A.N. 2001. Unilateral mandibular condylectomy in lambs. Br. J. Oral Maxillofac. Surg. 39: 304-309. [Medline] [CrossRef]

13. Miyamoto, H., Matsuura, H., Singh, J., and Goss, A.N. 2002. Regeneration of the mandibular condyle after unilateral condylectomy and myotomy of the masseter in lambs. Br. $J$. Oral Maxillofac. Surg. 40: 116-121. [Medline] [CrossRef]

14. Miyamoto, H., Shigematsu, H., Suzuki, S., and Sakashita, H. 2004. Regeneration of mandibular condyle following unilateral condylectomy in canines. J. Craniomaxillofac. Surg. 32: 296-302. [Medline] [CrossRef]

15. Nakagawa, S., Sakabe, J., Nakajima, I., and Akasaka, M. 2002. Relationship between functional disc position and mandibular displacement in adolescent females: posteroanterior cephalograms and magnetic resonance imaging retrospective study. J. Oral Rehabil. 29: 417-422. [Medline] [CrossRef]

16. Nakano, M., Fujita, T., Ohtani, J., Kawata, T., Kaku, M., Motokawa, M., Tsuka, N., Hayashi, H., and Tanne, K. 2009. Effects of mandibular advancement on growth after condylectomy. J. Dent. Res. 88: 261-265. [Medline] [CrossRef]

17. Nebbe, B., Major, P.W., and Prasad, N.G. 1998. Adolescent female craniofacial morphology associated with advanced bilateral TMJ disc displacement. Eur. J. Orthod. 20: 701712. [Medline] [CrossRef]

18. Rayne, J. and Crawford, G.N. 1972. The growth of the muscles of mastication in the rat. J. Anat. 113: 391-408. [Medline]

19. Schellhas, K.P., Pollei, S.R., and Wilkes, C.H. 1993. Pediatric internal derangements of the temporomandibular joint: effect on facial development. Am. J. Orthod. Dentofacial Orthop. 104: 51-59. [Medline] [CrossRef]

20. Tabe, H., Ueda, H.M., Kato, M., Nagaoka, K., Nakashima, Y., Matsumoto, E., Shikata, N., and Tanne, K. 2005. Influence of functional appliances on masticatory muscle activity. Angle Orthod. 75: 616-624. [Medline]

21. Wong, T.Y., Jin, Y.T., and Laskin, D.M. 1996. Autologous pericranial graft resurfacing after high condylectomy and discectomy of the temporomandibular joint in rabbits. $J$. Oral Maxillofac. Surg. 54: 747-752. [Medline] [CrossRef]

22. Yamada, K., Hiruma, Y., Hanada, K., Hayashi, T., Koyama, J., and Ito, J. 1999. Condylar bony change and craniofacial morphology in orthodontic patients with temporomandibular disorders (TMD) symptoms: a pilot study using helical computed tomography and magnetic resonance imaging. Clin. Orthod. Res. 2: 133-142. [Medline]

23. Yamada, K. 2009. Management of temporomandibular disorders in orthodontics. J. Kin-To. Orthod. Soc. 44: 1-6. 